\title{
Mindful Construal Reflections: Reducing Unhealthier Eating Choices
}

\author{
Misba Hussain ${ }^{1}\left[\right.$ [D $\cdot$ Helen Egan ${ }^{1} \cdot$ Rebecca Keyte $^{1} \cdot$ Michail Mantzios $^{1}$
}

Accepted: 21 April 2021 / Published online: 5 May 2021

(c) The Author(s) 2021

\begin{abstract}
Objectives Regularly choosing unhealthy energy-dense foods can have negative health consequences. The present study tested whether a mindful eating-specific tool, namely Mindful Construal Reflection (MCR), would promote healthier eating behaviors.

Methods Eighty-five university students were randomly assigned to either a mindfulness or control condition and were served M\&Ms and grapes as an unhealthy and healthy option respectively.

Results Participants in the mindfulness condition consumed significantly less M\&Ms than those in the control condition, but no significant differences were found in the consumption of grapes between the two conditions. Furthermore, control participants ate significantly more M\&Ms when displaying some hunger compared to those presenting no hunger, and although participants in the mindfulness condition also ate more when displaying some hunger, this did not reach statistical significance.

Conclusions Together, these results suggest that the MCR may be effective in reducing consumption of unhealthy energydense foods. However, future research is warranted in developing the MCR to encourage consumption of healthier food options.
\end{abstract}

Keywords Mindfulness $\cdot$ Mindful concrete construals $\cdot$ Food choice $\cdot$ Healthy eating $\cdot$ Unhealthy eating

Transition to university is a time of change and, on campus living, has been associated with poorer eating habits (Sprake et al., 2017; Tanton et al., 2015). Students often cite a lack of time, limited knowledge of how to prepare healthy foods, and easy access to unhealthy foods as barriers to healthy eating (Ashton et al., 2016; Escoto et al., 2012). Higher consumption of convenience and energy-dense foods has been associated with a lower intake of fruit and vegetables, and university students have been reported to consume well below the public health agency recommended five portions of fruit and vegetables per day (Small et al., 2013). Such unhealthy eating behaviors have shown to result in significant weight gain (Vadeboncoeur et al., 2015), which usually continues throughout adulthood. Therefore, interventions for healthy eating amongst student populations may be important and timely.

Misba Hussain

Misba.hussain@mail.bcu.ac.uk

Department of Psychology, Faculty of Business, Law and Social Sciences, Birmingham City University, The Curzon Building, 4 Cardigan St., Birmingham B4 7BD, UK
Typically, consumers make an average of over 200 foodrelated choices per day (Wansink \& Sobal, 2007), and such choices can be significantly affected by the "obesogenic environment" (Chaput et al., 2011). For example, research has shown that supermarkets' package sizing and restaurants and fast-food portions have all increased in recent years (Steenhuis \& Poelman, 2017; Wansink et al., 2009). However, eating habits are not only concerned with the amount that people eat but also the type of foods consumed. Indeed, the ubiquitous availability of high-energy foods can make healthy and low-caloric choices difficult (Hartmann et al., 2012). To improve eating behaviors, changes need to be made in dietary intake. For example, increasing fruit and vegetable intake and reducing the consumption of energydense foods can significantly aid in weight regulation (Hill et al., 2003). Therefore, investigating effective methods that encourage people to make healthier eating choices is essential.

Several studies have identified different methods in influencing the choice towards healthier eating habits, including the role of visual fields, social influences, and priming (Anschutz et al., 2008; Burger et al., 2010). Romero and 
Biswas (2016) found that healthier food options are significantly more likely to be selected when they are placed on the left visual field compared to the right visual field. The influence of descriptive social norms has been investigated and findings suggest that exposure to descriptive information of social norms leads participants to increasingly choose healthier eating options, such as increasing vegetable intake (Mollen et al., 2013; Robinson et al., 2014). Simple health primes have also shown to stimulate healthier eating behaviors, whereby diet cues in a TV commercial reduced unhealthy snack consumption among dieters (Anschutz et al., 2008). Similarly, exposing dieters to the cover of a health and diet magazine led participants to fewer hedonic food choices (Versluis \& Papies, 2016). Field findings also found that simple health primes reduced the purchase of energy-dense snacks by up to $75 \%$ among overweight and obese individuals (Papies et al., 2014). Such findings suggest that health primes can shift attention away from attractive high-caloric foods, and instead towards choosing healthier eating options, making priming a highly viable intervention tool for the facilitation of healthy food choices. However, enacting the elements of priming of one's own accord is not a clear-cut process. An intervention tool that actively enables people towards the act of priming may be required in order to maintain healthy eating behaviors (Mantzios \& Wilson, 2014).

Over recent years, mindfulness has been used as a successful intervention strategy in promoting healthier eating practices, such as reduced food cravings, decreased calorie intake, and loss and increased diet self-efficacy (Albert et al., 2010; Jenkins \& Tapper, 2013; Jordan et al., 2014; Timmerman \& Brown, 2012). Hunger can impact our attitudes towards food choices - typically boosting the attractiveness of energy-dense foods (Amin \& Mercer, 2016; Siep et al., 2009) and triggering automatic eating-orientated reactions (Papies et al., 2008). However, research has shown that mindful attention can help diminish the attractiveness towards such foods by viewing simulations of eating attractive but unhealthy foods as mere mental events, subsequently resulting in reduced unhealthy snacking (Marchiori $\&$ Papies, 2014).

Mindfulness has been described as an awareness that emerges through purposefully paying attention to what is taking place in the present moment with a non-judgmental attitude (Kabat-Zinn, 1990). Experimental studies have shown the practice of mindfulness to successfully encourage healthier eating behaviors (Papies et al., 2012, 2015) and display significant changes in weight loss (Hamilton et al., 2013; Mantzios \& Wilson, 2014). Findings from studies suggest that this positive impact occurs by assisting in the gradual change of external to internal eating and improving the ability to monitor and regulate dietary intake (Mantzios \& Giannou, 2014; Mantzios \& Wilson, 2014). In a number of studies, participants who reported higher levels of mindful eating reported increased intake of fruit and vegetable, a reduction in fat and sugar consumption, grazing, and reduced motivations to eat palatable foods (e.g., Gilbert \& Waltz, 2010; Mantzios et al., 2018). Taken together, these findings provide strong evidence that mindfulness can encourage healthier eating behaviors and on a practical level gives guidance as to how consumers can enhance their responsiveness to hunger and satiety cues (Jordan et al., 2014).

The majority of experimental studies on eating behaviors use body scan exercises or short audio recording of mindful instructions. However, current evidence within literature suggests that eating-specific mindful exercises may be more effective in promoting healthier eating behaviors and weight loss than generic mindfulness practices as they are more behavioral relevant (Mantzios \& Wilson, 2015). Mantzios and Wilson (2014) developed the Mindful Construal Diary (MCD) which combined the theoretical concepts of both mindfulness and construal level theory (CLT). CLT describes an identification on a close or distant continuum (Liberman \& Trope, 1998). While close objects, events, or individuals are represented as concrete, distant objects, events, and individuals are portrayed as abstract. Abstract construals consider why actions are being performed, whereas concrete construals focus on how they carry out behavior (Freitas et al., 2004). As abstract construals are described using a temporal distancing technique, this makes them unsuitable in the development of mindfulness for two main reasons (see Manztios \& Wilson, 2014). Firstly, abstract mindsets involve ruminative, judgmental, and uncertain thinking, and these are mechanisms that are often involved in psychological distress (Galfin \& Waltkins, 2011). Secondly, by focusing on the why elements of a given situation, one's concern of the present moment would be periodical (Fujita, 2008). In contrast, concrete construals promote present-focused orientation and rarely entail judgment or rumination, elements primarily descriptive of mindfulness (Kabat-Zinn, 1990; Schmeichel et al., 2011). Research has indeed found interacting with the MCD (i.e., writing out the answers to the mindful construal questions while eating) assisted with weight regulation (Mantzios \& Wilson, 2014), and related research found reflecting on the mindful construal method (i.e., simply considering the answers to the mindful construal questions while eating) improved state levels of mindfulness, self-compassion, and anxiety (Hussein et al., 2017). In essence, Hussein et al.'s (2017) research led to transforming the MCD to a tool of reflection, henceforth referred to as Mindful Construal Reflection (MCR), which could promote healthier eating choices and explain weight regulation observed in past research.

This study investigated the theoretical conceptualization of concrete construals and mindfulness upon healthier eating 
behaviors. Firstly, it was hypothesized that participants who engaged with the MCR by simply reading and reflecting on the questions would be less likely to choose unhealthier food options than participants in a control condition. Secondly, it was predicted that the consumption of unhealthy foods may be higher for participants who are hungry compared to those who are not, but using the MCR will significantly reduce intake of unhealthy food when hungry.

\section{Method}

\section{Participants}

Eighty-five students attending a university in the West Midlands, UK, were enrolled through an online research participation website. Forty-three participants were randomly allocated to the mindfulness condition and 42 to the control condition. The sample consisted of 72 females and 13 males, with an average BMI of $M=24.54(S D=7.23)$ and an age of $M=20.11$ years $(S D=3.51)$. Participants self-identified ethnicities were White or White British $(n=39)$, Black African or Caribbean $(n=12)$, Asian $(n=26)$, mixed ethnicity $(n=6)$, and Arab $(n=2)$. The study was approved by the University's ethical committee, and informed consent was gained from all participants.

Eligibility Participants were informed via an information sheet and consent form that they were not eligible to participate if they had any nut allergies or if they had been diagnosed with an eating disorder.

\section{Procedures}

Enrolment The study was advertised as an experiment regarding affective responses to food tasting, and was deliberately kept vague in order to prevent people from predicting the true aim of the study. Experimental sessions took place between 12 and $4 \mathrm{pm}$ and lasted approximately $25 \mathrm{~min}$, and participants received course credit for their participation. Upon arrival, participants were randomly assigned to either the mindfulness or control condition. Participants received an information sheet and after providing informed consent, they were seated in individual cubicles in an experimental laboratory.

Experimental Procedure Participants were first asked to provide their height and weight in centimeters and kilograms using a stadiometer and a digital scale, and they were then asked to complete a set of demographic questions and a state mindfulness scale (SMS; Tanay \& Bernstein, 2013). Next, depending on the condition, participants were asked to read the MCR or a newspaper article (concerning diesel cars) for 2 min prior to receiving the M\&Ms and grapes in order to familiarize themselves with the reading materials. The newspaper article was selected due to its similarity in length of the MCR as well as its absence of food or eating-related matters. Participants were then provided with a portion of M\&Ms and a portion of grapes and asked to continue engaging in the reading while eating for another $5 \mathrm{~min}$. A total 7-min framework to read and engage with the MCR was deemed to be appropriate based on previous research that has shown a similar time frame to result in significant improvements in state mindfulness, self-compassion, and anxiety (Hussein et al., 2017). Participants in the control condition also engaged with the newspaper article for the same amount of time. Participants were told they could choose any option of food they wanted (or both) and eat as much as they liked. After 5 min, the experimenter asked participants to finish eating and they were asked to complete another SMS, as well as questionnaires regarding trait mindfulness, trait mindful eating, and eating behaviors. Once the experiment was completed and participants had finished answering the questionnaires, the experimenter carried out a funneled debriefing in order to assess whether any participants were aware of the aims of the study. The funneled debriefing began with a general format of "During the process of completing the questionnaires, did you notice anything in particular?" to more specific questions "If you were to guess, what would you assume was the aim of this study?" Finally, participants were debriefed and thanked for their participation.

Intervention-Use of Mindful Construal Reflection The MCR (and MCD) have previously shown to improve mindfulness longitudinally and within experimental settings (Hussein et al., 2017; see Mantzios \& Wilson, 2014). Similar to MCD, MCR is a tool consisting of a total of 13 questions, with the first three questions focusing specifically on the taste, texture, and smell of the food, and the remaining 10 questions combining elements of concrete construal, mindful awareness, and self-compassion. Sample items of the tool include "How understanding and patient am I now that thoughts and feelings are intruding on this pleasurable experience?" and "How do you feel and what passes through your mind now that you are eating this snack?" (see Table 1 for the full list of questions). While the MCD requires participants to write out their answers to the mindful construal questions, the MCR simply involves participants to consider their answers to the questions (Hussein et al., 2017; Mantzios \& Wilson, 2014). Participants in the current study were first presented with a sheet of paper containing instructions and questions to the MCR, and they were then asked to read the MCR for 2 min before they started eating in order to familiarize themselves with the intervention. Next, 
Table 1 Questions presented to participants in the mindfulness condition

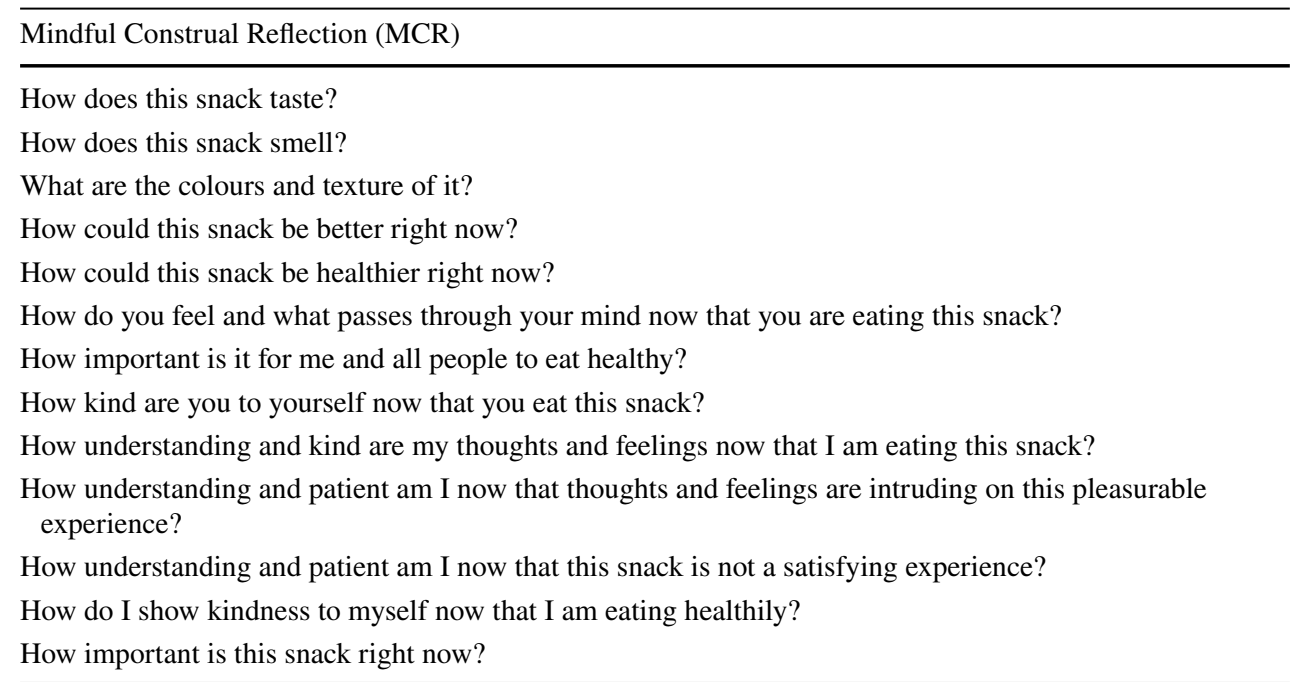

participants were asked to simply consider their answers for $5 \mathrm{~min}$ by re-reading the questions while they were eating.

Food Participants in both the mindfulness and control conditions were provided with a $100 \mathrm{~g}$ of peanut M\&Ms (approximately $512 \mathrm{kcal}$ ) and a $100 \mathrm{~g}$ of green and red grapes (approximately $72 \mathrm{kcal}$ ). Although a typical serving size in the UK is approximately $45 \mathrm{~g}$, a serving of $100 \mathrm{~g}$ was provided in this experiment in order to avoid artificially limited intake. The M\&Ms and grapes were served in two separate white bowls $(15 \mathrm{~cm} \times 15 \mathrm{~cm} \times 8 \mathrm{~cm})$ presented to participants in front of them. All food was brought from UK Tesco stores.

\section{Measures}

Participant Information Form Participants were asked questions relating to their age, height, weight, gender, and ethnicity. Such measures were taken in order to gain an insight on participant characteristics and establish whether such factors could have an effect on the final results.

Previous Day and Usual Day Intake of Fruit and Vegetable To assess daily fruit and vegetable consumptions, participants were asked "How many portions of fruit and vegetables did you eat yesterday?" and "How many portions of fruit and vegetable do you normally eat a day?" This measure has been similarly used in previous research (Robinson et al., 2014).

Hunger In order to assess baseline hunger, participants were asked "How hungry are you right now?" and presented with the following number and label responses: 1 (not at all hungry), 2 (slightly hungry), 3 (moderately hungry), 4 (very hungry), and 5 (extremely hungry). Lower scores represented lower levels of hunger and higher scores represented higher levels of hunger.

Three-Factor Eating Questionnaire (Stunkard \& Messick, 1985) The Three-Factor Eating Questionnaire (TFEQ) used in this study was an 18-item instrument created from the translated Swedish version of the original TFEQ (Karlsson et al., 2000). The scale is composed of three subscales: cognitive restraint, uncontrolled eating, and emotional eating. Responses range from 1 (definitely false) to 4 (definitely true), and items include "I deliberately take small helpings as a means of controlling my weight" and "When I feel blue, I often overeat". The present study produced the following alphas: cognitive restraint ( $\alpha=0.75)$, uncontrolled eating ( $\alpha=0.87)$, emotional eating ( $\alpha=0.79)$, and overall score $(\alpha=0.82)$.

Mindful Eating Scale (Hulbert-Williams et al., 2013) The Mindful Eating Scale (MES) is a 28-item instrument with responses ranging from 1 (never) to 4 (usually) and overall scores ranging from 28 to 112 . Sample items include "I need to eat like clockwork" and "When I get hungry, I can't think about anything else". The present study produced an alpha of $\alpha=0.80$.

Five Facet Mindfulness Questionnaire: Short Form (Bohlmeijer et al., 2011) The Five Facet Mindfulness Questionnaire: Short Form (FFMQ-SF) is a 24-item scale that originates from the five facet mindfulness questionnaire (Baer et al., 2004). The scale includes items such as "When I have distressing thoughts or images, I don't let myself be carried away by them" and "I rush through activities without being really attentive to them". Each item is scored from 1 (never or very rarely true) to 5 (very often or always true), with 
overall scores range from 24 to 120 . The present study produced an alpha of $\alpha=0.83$.

State Mindfulness Scale (Tanay \& Bernstein, 2013) The State Mindfulness Scale (SMS) is a 21-item self-report measure that reflects on traditional and contemporary psychological science models of mindfulness. Responses range from 1 (not at all) to 5 (very well), with total scores varying from 21 to 105. It includes items such as "I felt that I was experiencing the present moment fully" and "I felt aware of what was happening inside of me". Participants were asked to complete a state measure before receiving the reading materials, M\&Ms and grapes, and this measure was based on how they felt in the last 5 to $10 \mathrm{~min}$ (prior to the experiment). Participants also completed another SMS after the reading and eating task and were similarly instructed to base their answers again on how they felt in the last 5 to $10 \mathrm{~min}$. The scale has shown to be an effective assessment tool (Hussein et al., 2017). The present study produced the following alphas: pre $(\alpha=0.94)$ and post $(\alpha=0.94)$ conditions.

\section{Data Analyses}

Consumption of each food was measured in grams, and it was calculated using the difference in weight of each bowl before and after each experimental session. Calories (kCal) consumed were calculated by multiplying the weight of the fruit by 0.72 and multiplying the weight of the chocolate by 5.12. Chi-square was also used to account for differences in gender and food choice between conditions. A $2 \times 2$ ANOVA was planned to test whether an improvement in state mindfulness scores was observed. $T$-tests were conducted to test for differences in age, BMI, hunger, previous and usual day fruit/vegetable intake, total TFEQ, TFEQ subscales (e.g., cognitive restraint, uncontrolled eating, and emotional eating), MES, FFMQ, and to compare mean values of food intake from M\&Ms and grapes consumed between the two conditions. ANCOVA was used to control for such variables in subsequent analyses. The hunger scale used as a covariate was initially run as a continuous variable, and a split on the hunger scale was then conducted gaining a dichotomous variable. Participants who scored at a 1 (not at all hungry) were categorized as having no hunger, and those who scored at a 2 or above (slightly hungry or more) were categorized as having some hunger. Any significant covariates were followed up with the $t$-tests and Mann-Whitney $U$ tests. All analyses were conducted using SPSS v24.

\section{Results}

The funneled debriefing procedure indicated that participants were not aware of the aims of the study. Chisquare analysis showed that gender did not significantly differ between the mindfulness and control conditions, $\chi^{2}$ $(1)=0.07, p=0.80$. Eighteen participants were labelled as having no hunger (mindfulness $n=8$; control $n=10$ ) and 67 participants were identified as having some hunger (mindfulness $n=35$; control $n=32$ [slightly hungry: mindfulness $n=16$, control $n=20$; moderately hungry: mindfulness $n=15$, control $n=9$; very hungry: mindfulness $n=3$, control $n=3$; extremely hungry: mindfulness $n=1$, control $n=0]$ ]). $T$-tests were also conducted to test for differences in participant characteristics, such as age, BMI, hunger, previous and usual day fruit/vegetable intake, total TFEQ, TFEQ subscales (e.g., cognitive restraint, uncontrolled eating, and emotional eating), MES, and FFMQ. As Table 2 shows, there were no significant differences found between the two conditions regarding such characteristics: all $p>0.20$. All characteristics were included as covariates
Table 2 Means, Standard Deviations, and Significance Values of Variables

\begin{tabular}{|c|c|c|c|}
\hline & $\begin{array}{l}M,(S D) \text { - mindfulness } \\
(n=43)\end{array}$ & $\begin{array}{l}M,(S D) \text {-control } \\
(n=42)\end{array}$ & $p$ \\
\hline Age & $19.93(1.58)$ & $20.29(4.75)$ & .64 \\
\hline BMI & $24.07(7.60)$ & $25.02(6.88)$ & .55 \\
\hline Previous day fruit/vegetable intake & $2.56(1.25)$ & $2.56(1.98)$ & .99 \\
\hline Usual day Fruit/vegetable intake & $2.00(1.45)$ & $2.00(1.82)$ & 1.00 \\
\hline Hunger & $2.37(.95)$ & $2.12(.86)$ & .20 \\
\hline Total TFEQ & $40.63(10.09)$ & $40.17(8.15)$ & .82 \\
\hline Cognitive restraint ${ }^{\mathrm{a}}$ & $11.98(3.82)$ & $12.67(3,92)$ & .41 \\
\hline Uncontrolled eating $^{\mathrm{a}}$ & $21.37(6.55)$ & $20.67(6.48)$ & .62 \\
\hline Emotional eating $^{\mathrm{a}}$ & $7.28(2.87)$ & $6.83(2.37)$ & .44 \\
\hline MES & $75.44(10.32)$ & $76.19(10.10)$ & .74 \\
\hline FFMQ & $56.79(9.95)$ & $57.71(10.35)$ & .68 \\
\hline Pre SMS & $64.86(16.53)$ & $66.50(16.39)$ & .65 \\
\hline
\end{tabular}

${ }^{\mathrm{a}}$ TFEQ subscale 
Table 3 Food selected by percentage of participants

\begin{tabular}{lllll}
\hline & M\&Ms & Grapes & Both & None \\
\hline Mindfulness $(n=43)$ & $14 \%$ & $41.9 \%$ & $41.9 \%$ & $2.2 \%$ \\
Control $(n=42)$ & $16.7 \%$ & $38.1 \%$ & $42.9 \%$ & $2.3 \%$ \\
\hline
\end{tabular}

Note: values displayed on this table were not significantly different

using ANCOVA, and they showed to have no significant effect (except hunger) on the observed results for either grapes or M\&M consumption.

\section{State Mindfulness}

A 2 (condition: mindfulness, control) $\times 2$ (time: pre, post) mixed design ANOVA was carried out, with the condition being a between subjects factor and the time being a repeated measures factor. There was a significant main effect of time $F(1,83)=4.15, p=0.05, \eta_{\mathrm{p}}{ }^{2}=0.05$, and as predicted, state mindfulness significantly increased in the mindfulness condition but did not change in the control condition (mindfulness condition: post $M=73.23$, $S D=17.37)$. There was also a significant interaction between the condition and time $F(1,83)=4.40, p=0.04$, $\eta_{\mathrm{p}}{ }^{2}=0.05$. The main effect between conditions was not significant $F(1,83)=0.80, p=0.38$.

\section{Food Choice}

The food choices between the mindfulness and control conditions were highly similar, with approximately $42 \%$ eating some of both foods, and approximately $15 \%$ choosing only M\&Ms, $\chi^{2}(3)=0.18, p=0.98$ (see Table 3).

\section{Food Consumption}

Independent-sample $t$-tests were conducted separately to compare the amount of each food consumed between the mindfulness and control conditions. There was a significant difference in the consumption of M\&Ms between the two conditions, with the mindfulness condition consuming significantly less M\&Ms (grams: $M=9.42, S D=13.19$; kCal: $M=48.22, S D=67.55$ ) than the control condition (grams: $M=18.45, S D=20.11$; kCal: $M=94.48, S D=102.95)$; $t(70.5)=-2.44, p=0.02, d=0.53$ (see Figs. 1 and 2). There was no significant difference found in the consumption of grapes between the mindfulness condition (grams: $M=37.91, S D=31.02$; kCal: $M=27.29, S D=22.33$ ) and control condition (grams: $M=29.76, S D=29.53$; kCal: $M=21.43, S D=21.26$ ); $t(83)=1.24, p=0.22$ (see Figs. 1 and 2).

\section{Effects of Hunger}

Hunger was used as a covariate to test the effect that it may have had upon participants' consumption of M\&Ms and grapes. A between-subject ANCOVA revealed that hunger had a significant effect upon the amount of M\&Ms consumed $F(1,82)=4.04, p=0.05, \eta_{p}^{2}=0.05$, but had no significant effect on the amount of grapes consumed $F(1$, $82)=1.12, p=0.29$. The significant effect of hunger on the amount of M\&Ms consumed was followed up by $t$-tests, as well as non-parametric tests, namely the Mann-Whitney $U$, due to the rather skewed distribution.

No Hunger and M\&M Consumption An independent-sample $t$-test and Mann-Whitney $U$ was conducted to compare the amount of M\&Ms consumed between the mindfulness and control conditions in participants with no hunger.
Fig. 1 Consumption of M\&Ms and grapes in grams across mindfulness $(n=43)$ and control $(n=42)$ conditions. Error bars refer to the standard error of the mean

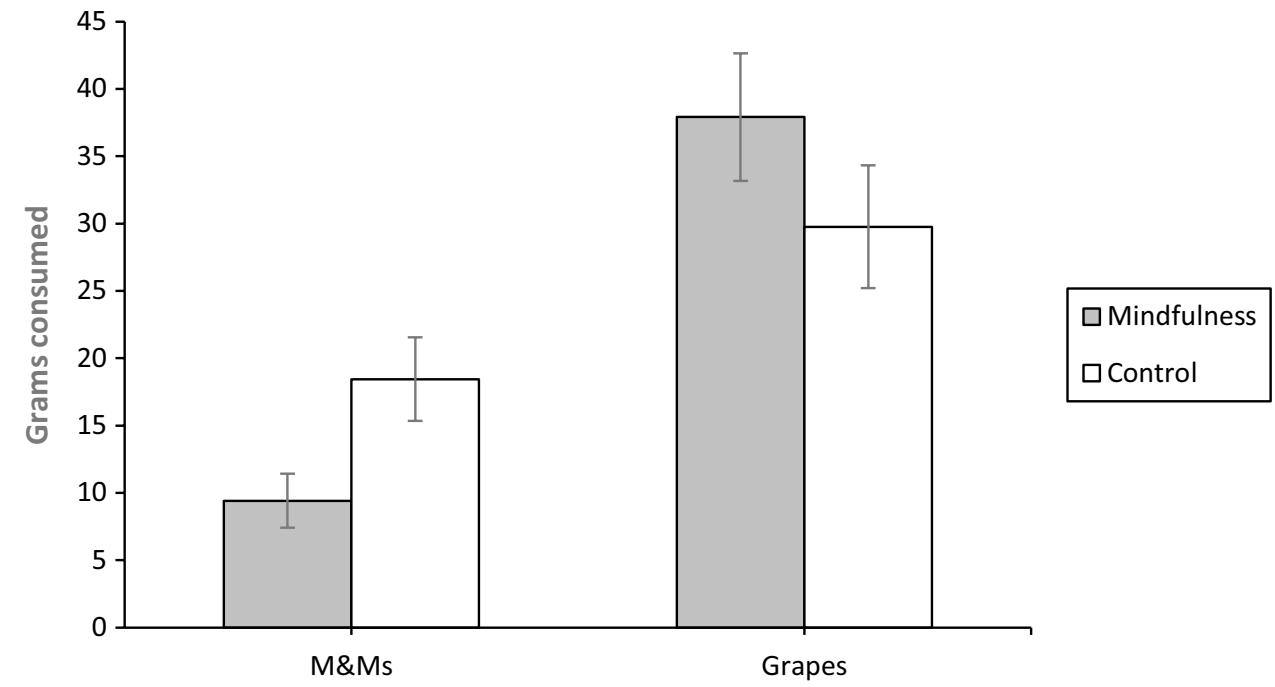


Fig. 2 Consumption of M\&Ms and grapes in $\mathrm{kCal}$ across mindfulness $(n=43)$ and control $(n=42)$ conditions. Error bars refer to the standard error of the mean

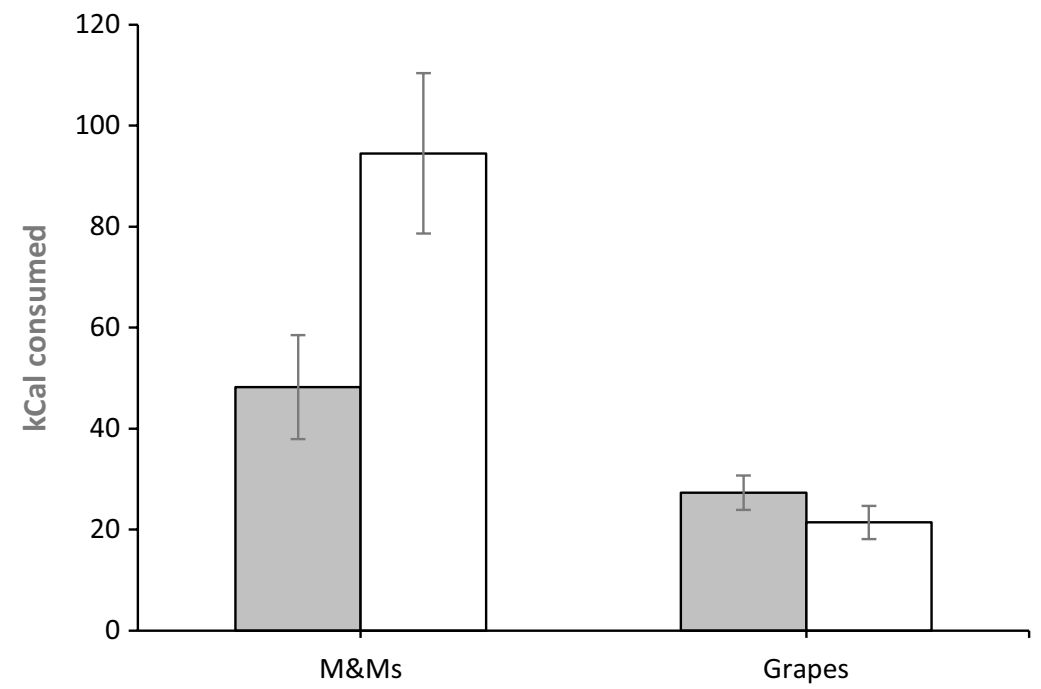

$\square$ Mindfulness

$\square$ Control
There was no significant difference found in the consumption of M\&Ms between the mindfulness condition (grams: $M=4.38, S D=7.29$; kCal: $M=22.40, S D=37.32$ ) and control condition (grams: $M=7.00, S D=9.19$; kCal; $M=35.84$, $S D=47.05) ; t(16)=-0.66, p=0.52 ; U=33.50, p=0.53$ (see Fig. 3).

Some Hunger and M\&M Consumption An independent-sample $t$-test and Mann-Whitney $U$ was conducted to compare the amount of M\&Ms consumed between the mindfulness and control condition in participants with some hunger. There was a significant difference found in the proportion of M\&Ms consumed between the two conditions, with the mindfulness condition consuming significantly less M\&Ms (grams: $M=10.57, S D=14.03$; kCal: $M=54.13$, $S D=71.81$ ) than the control condition (grams: $M=22.03$,
$S D=21.32: \mathrm{kCal}: M=112.81, S D=109.17) ; t(52.84)=2.57$, $p=0.01, d=0.64 ; U=381.50, p=0.02$ (see Fig. 3).

Effect of Hunger on M\&M Consumption by Condition Furthermore, independent-sample $t$-tests and Mann-Whitney $U$ were conducted separately to explore consumption of M\&Ms between participants who displayed no hunger and some hunger within the control and mindfulness conditions. There was a significant difference in consumption of M\&Ms within the control condition, with participants who displayed no hunger consuming significantly less M\&Ms than those who presented with some hunger, $t(35.55)=3.16, p=0.003, d=0.92$; $U=92.00, p=0.04$. There was no significant difference in consumption of M\&Ms within the mindfulness condition between participants who displayed no hunger and some hunger, $t(41)=1.21, p=0.24 ; U=106.00, p=0.26$ (see Fig. 3).
Fig. 3 Consumption of M\&Ms in $\mathrm{kCal}$ across mindfulness-no hunger $(n=8)$, control-no hunger $(n=10)$, mindfulnesssome hunger $(n=35)$, and control-some hunger $(n=32)$. Error bars refer to the standard error of the mean

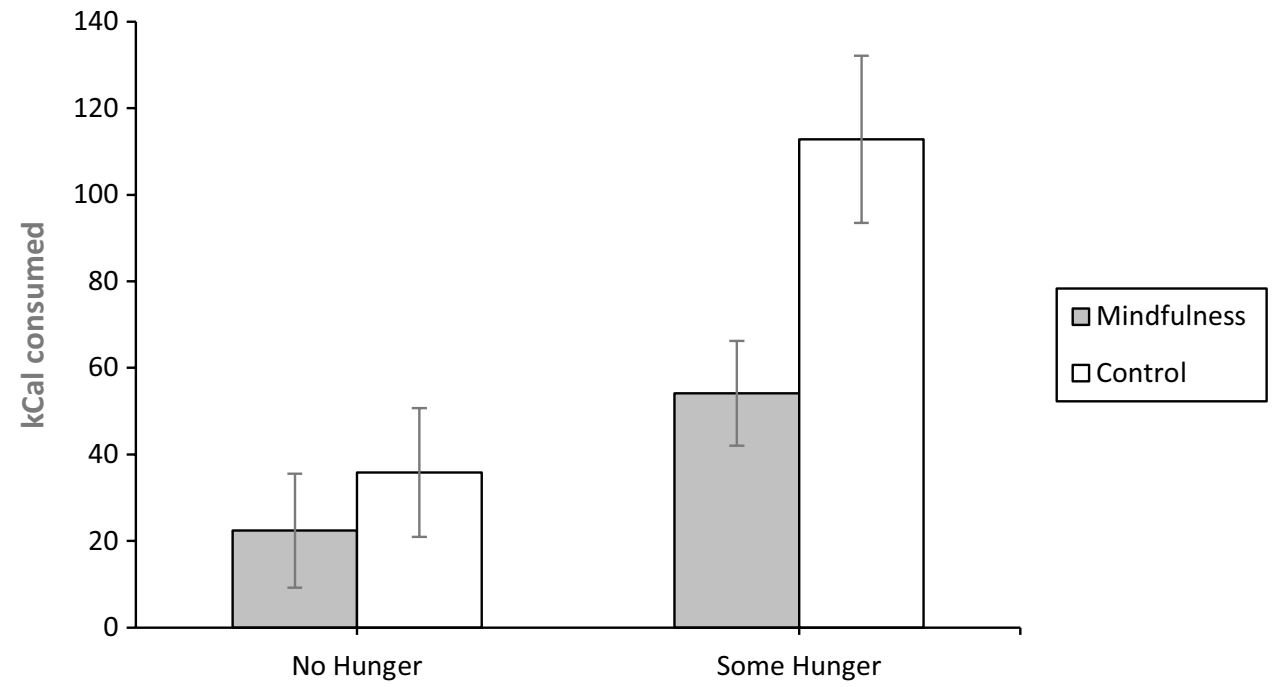




\section{Discussion}

The present study examined whether the Mindful Construal Reflection could be an effective tool in promoting healthier food choices. The findings suggest participants in the mindfulness condition ate significantly less M\&Ms than participants in the control condition, but no significant differences were found in the consumption of grapes between the two conditions. Furthermore, control participants ate significantly more M\&Ms when displaying some hunger compared to those presenting no hunger, and participants in the mindfulness condition also ate more when displaying some hunger, though this did not reach statistical significance. Other characteristics such as age, BMI, previous and usual day fruit/vegetable intake, total TFEQ, TFEQ subscales (e.g., cognitive restraint, uncontrolled eating, and emotional eating), MES, and FFMQ were tested as covariates, and they had no significant effect on the findings. Collectively results suggest that utilizing the MCR may function as an effective method in reducing unhealthy eating.

Results are explained through three potential avenues. First, the procedure of reading and reflecting on the MCR may have led participants to consume less M\&Ms because they may have placed a greater focus upon their internal cues of hunger and considered the nutritious elements of the food instead of simply focusing on the attractiveness of the food. The engagement of the MCR and considering questions related to their hunger, taste, and healthiness of the snack may have been sufficient to overcome the initial temptation of selecting the M\&Ms, thus resulting in a reduced consumption of M\&Ms. This is supported by research that has suggested that encouraging participants to be aware of and rely on internal signals of hunger and satiety might reduce the influence of external cues, such as attractiveness, which may in turn diminish the effects of unhealthy eating (Dalen et al., 2010).

Secondly, the mindful intervention used in this study was an eating-specific exercise, and the focus of the intervention was to be mindfully aware of the taste, texture, likability, and healthiness of the food being consumed. Jordan et al. (2014) suggested that even without mindful eating-specific instructions, mindfulness can encourage healthier eating; this study suggests that engaging with the MCR is perhaps more effective for healthier eating than generic mindfulness techniques or other eating-specific mindful methods (see also Kabat-Zinn, 2006; Mantzios \& Wilson, 2015). The MCR is suggested to enable participants to adopt a mindful eating attitude, that is being aware of what they are eating and placing a focus on its nutritious benefits which then enables healthier eating choices. This method may also offer a more accessible and sustainable technique to be applied at each meal/snack than a body scan exercise, which is not eating-specific, and while there is evidence for accessibility and efficacy of the body scan exercise (Al-Chalabi et al., 2008), for some people, it may be seen as more effortful. Furthermore, even in the case of using an eating-specific method, such as guided recordings of the mindful eating-raisin exercise (Kabat-Zinn, 2006), there is clear evidence for promoting healthier eating behaviors (e.g., Hong et al., 2011, 2014). However, the original recording is 17 min long (Kabat-Zinn, 2006), and although other researchers have used a shorter version of the recording lasting $10 \mathrm{~min}$ (Hong et al., 2011), this may still be too long to practice before every meal. As such, listening to a recorded message may not be as feasible in comparison to perhaps the MCR which can be quickly read and reflected upon.

Thirdly, participants may have found it easier to engage with the MCR as it was used as a priming tool. Previous research on priming has shown its success in promoting healthier eating behaviors (e.g., Papies et al., 2014). The act of allowing participants to simply read and consider the answers to the questions rather than writing out answers could act as a more mindful and less distracting approach towards eating, thus consciously leading towards healthier eating behaviors.

\section{Limitations and Future Research}

There are some potential limitations to the present study that require further attention. Firstly, while consumption of M\&Ms was reduced in the mindfulness condition, consumption of grapes did not increase. This could suggest that the MCR may be beneficial for reducing unhealthy eating (i.e., high fat and sugar foods), but may not necessarily encourage consumption of healthier food options (i.e., fruit). Further research should investigate methods that can be applied within the MCR that encourage the consumption of fruit (or other healthier food options, such as vegetables).

Moreover, the present study was conducted on relatively lean and highly educated students, while previous studies have indicated that people who are overweight or obese are more likely to engage in energy-dense snacking (Hartmann et al., 2012). In order to better understand the potential of this intervention, future research should specifically focus on populations at risk and in need for such interventions, as the engagement and acceptability in such populations is of primary importance.

Furthermore, this study was conducted in a highly controlled laboratory, and real-life situations may not be so clear-cut when it comes to choosing between healthy and 
unhealthy foods. However, the long-term application of using Mindful Construal Diary within home and personal settings did find significant improvements in weight loss, suggesting people are able to implement it within their daily life (Mantzios \& Wilson, 2014). The MCR in essence requires less time, commitment and effort, and adopting healthier eating choices may indeed come through this short and accessible mindfulness practice (Mantzios \& Giannou, 2018). However, further long-term follow-ups are essential in concretely determining the impact of the MCR upon participants' eating behaviors and weight loss (Mantzios \& Wilson, 2015).

Finally, the MCR (and MCD) has previously demonstrated an ability in increasing people's self-compassion (Hussein et al., 2017; Mantzios \& Wilson, 2014). Selfcompassion is described as taking a kinder approach to oneself with a mindful awareness and consideration of personal difficulties as being part of a shared humanity that everyone experiences (Neff, 2003). Both mindfulness and self-compassion appear to be inter-related, with literature suggesting that the combination of both capacities tends to improve psychological well-being and weight loss (e.g., Neff \& Germer, 2013; Mantzios \& Wilson, 2015). Recent research has looked into the component of self-kindness within self-compassion and found wide variations in behaviors (Egan \& Mantzios, 2017). In their research, they found that the act of self-kindness for some people involved binge drinking or over-indulging on their favorite foods, and for others, it consisted of taking a warm bath or eating a healthy meal (Egan \& Mantzios, 2017). They explained that the former group displays behavior that may lead to negative health consequences and only refers to a perceived sense being "kind" to the mind (i.e., one's thoughts, feelings, and emotions), while the latter group displays behaviors that relate to self-kindness of both the mind and body (i.e. psychological and physiological self-kindness; Egan \& Mantzios, 2017) and, therefore, is perhaps a truer model of self-compassion and the golden standard of self-care (Neff, 2003, 2009). Future research should investigate how the state of self-kindness combined with mindfulness could influence eating choices and behaviors via experimental settings.

The findings from the present study indicate that utilizing and engaging with the MCR may be an effective method in encouraging healthier eating behaviors by reducing consumption of foods high in fat and sugar. However, future research should investigate the use of the MCR among varied populations as well as apply strategies that encourage consumption of healthier food options.

Author Contribution MH designed the study, collected data, conducted data analyses, and wrote the manuscript. HE, RK, and MM supported the study and reviewed the manuscript. All authors gave their final approval of the manuscript.

\section{Declarations}

Ethics Approval All procedures have been approved by the institutional research committee at Birmingham City University and have been performed in accordance with the ethical standards laid down in the 1964 Declaration of Helsinki and its later amendments.

Informed Consent Informed consent was obtained from all individual participants included in this study.

Conflict of Interest The authors declare that they have no conflict of interest.

Open Access This article is licensed under a Creative Commons Attribution 4.0 International License, which permits use, sharing, adaptation, distribution and reproduction in any medium or format, as long as you give appropriate credit to the original author(s) and the source, provide a link to the Creative Commons licence, and indicate if changes were made. The images or other third party material in this article are included in the article's Creative Commons licence, unless indicated otherwise in a credit line to the material. If material is not included in the article's Creative Commons licence and your intended use is not permitted by statutory regulation or exceeds the permitted use, you will need to obtain permission directly from the copyright holder. To view a copy of this licence, visit http://creativecommons.org/licenses/by/4.0/.

\section{References}

Al-Chalabi, L., Prasad, N., Steed, L., Stenner, S., Aveyard, P., Beach, J., \& Ussher, M. (2008). A pilot randomised controlled trial of the feasibility of using body scan and isometric exercises for reducing urge to smoke in a smoking cessation clinic. BMC Public Health, $8(1), 349$

Albert, H., Mulkens, S., Smeets, M., \& Thewissen, R. (2010). Coping with food cravings. Investigating the potential of a mindfulnessbased intervention. Appetite, 55(1), 160-163

Amin, T., \& Mercer, J. (2016). Hunger and satiety mechanisms and their potential exploitation in the regulation of food intake. Current Obesity Reports, 5(1), 106-112

Anschutz, D., Van Strien, T., \& Engels, R. (2008). Exposure to slim images in mass media: Television commercials as reminders of restriction in restrained eaters. Psychology of Popular Media Culture, 1, 48-59

Ashton, L., Hutchesson, M., Rollo, M., Morgan, P., \& Collins, C. (2016). Motivators and barriers to engaging in healthy eating and physical activity. American Journal of Men's Health, 11(2), 330-343

Baer, R., Smith, G., \& Allen, K. (2004). Assessment of mindfulness by self-report. Assessment, 11(3), 191-206

Bohlmeijer, E., ten Klooster, P., Fledderus, M., Veehof, M., \& Baer, R. (2011). Psychometric properties of the five facet mindfulness questionnaire in depressed adults and development of a short form. Assessment, 18(3), 308-320

Burger, J., Bell, H., Harvey, K., Johnson, J., Stewart, C., Dorian, K., \& Swedroe, M. (2010). Nutritious or delicious? The effect of descriptive norm information on food choice. Journal of Social and Clinical Psychology, 29(2), 228-242 
Chaput, J., Klingenberg, L., Astrup, A., \& Sjödin, A. (2011). Modern sedentary activities promote overconsumption of food in our current obesogenic environment. Obesity Reviews, 12(5), e12-e20

Dalen, J., Smith, B., Shelley, B., Sloan, A., Leahigh, L., \& Begay, D. (2010). Pilot study: Mindful eating and living (MEAL): Weight, eating behavior, and psychological outcomes associated with a mindfulness- based intervention for people with obesity. Complementary Therapies in Medicine, 18(6), 260-264

Egan, H., \& Mantzios, M. (2017). On the role of self-compassion and self-kindness in weight regulation and health behavior change. Frontiers in Psychology, 8, 229-242

Escoto, K., Laska, M., Larson, N., Neumark-Sztainer, D., \& Hannan, P. (2012). Work hours and perceived time barriers to healthful eating among young adults. American Journal of Health Behavior, 36(6), 786-796

Freitas, A. L., Gollwitzer, P. M., \& Trope, Y. (2004). The influence of abstract and concrete mindsets on anticipating and guiding others self-regulatory efforts. Journal of Experimental Social Psychology, 40(6), 739-752

Fujita, K. (2008). Seeing the forest beyond the trees: A construal level approach to self-control. Social and Personality Psychology Compass, 2(3), 1475-1496

Galfin, J., \& Watkins, E. (2011). Construal level, rumination, and psychological distress in palliative care. Psycho-Oncology, 21(6), 680-683

Gilbert, D., \& Waltz, J. (2010). Mindfulness and health behaviors. Mindfulness, 1(4), 227-234

Hamilton, J., Fawson, S., May, J., Andrade, J., \& Kavanagh, D. (2013). Brief guided imagery and body scanning interventions reduce food cravings. Appetite, 71, 158-162

Hartmann, C., Siegrist, M., \& van der Horst, K. (2012). Snack frequency: Associations with healthy and unhealthy food choices. Public Health Nutrition, 16(08), 1487-1496

Hill, J., Wyatt, H., Reed, G., \& Peters, J. (2003). Obesity and the environment: Where do we go from here? Science, 299(5608), 853-855

Hong, P. Y., Lishner, D. A., Han, K. H., \& Huss, E. A. (2011). The positive impact of mindful eating on expectations of food liking. Mindfulness, 2(2), 103-113

Hong, P. Y., Lishner, D. A., \& Han, K. H. (2014). Mindfulness and eating: An experiment examining the effect of mindful raisin eating on the enjoyment of sampled food. Mindfulness, 5(1), 80-87

Hulbert-Williams, L., Nicholls, W., Joy, J., \& Hulbert-Williams, N. (2013). Initial validation of the mindful eatHussaining scale. Mindfulness, 5(6), 719-729

Hussein, M., Egan, H., \& Mantzios, M. (2017). Mindful Construal Diaries: A less anxious, more mindful, and more self-compassionate method of eating. Sage.

Jenkins, K., \& Tapper, K. (2013). Resisting chocolate temptation using a brief mindfulness strategy. British Journal Of Health Psychology, 19(3), 509-522

Jordan, C., Wang, W., Donatoni, L., \& Meier, B. (2014). Mindful eating: Trait and state mindfulness predict healthier eating behavior. Personality and Individual Differences, 68, 107-111

Kabat-Zinn, J. (1990). Full catastrophe living: Using the wisdom of your body and mind to face stress, pain and illness. Delacourt.

Kabat-Zinn, J. (2006). Eating meditation. On mindfulness for beginners $[C D]$. Sounds True Inc.

Karlsson, J., Persson, L., Sjöström, L., \& Sullivan, M. (2000). Psychometric properties and factor structure of the Three-Factor Eating Questionnaire (TFEQ) in obese men and women. Results from the Swedish obese subjects (SOS) study. International Journal Of Obesity, 24(12), 1715-1725

Liberman, N., \& Trope, Y. (1998). The role of feasibility and desirability considerations in near and distant future decisions: A test of temporal construal theory. Journal of Personality And Social Psychology, 75(1), 5-18

Mantzios, M., \& Giannou, K. (2014). Group vs. single mindfulness meditation: Exploring avoidance, impulsivity, and weight management in two separate mindfulness meditation settings. Applied Psychology: Health and Well-Being, 6(2), 173-191

Mantzios, M., \& Wilson, J. (2014). How concrete construals can become mindful: A novel approach of developing mindfulness and self-compassion to assist weight loss. Psychology and Health, 29(4), 1-21

Mantzios, M., \& Wilson, J. C. (2015). Exploring mindfulness and mindfulness with self-compassion-centered interventions to assist weight loss: Theoretical considerations and preliminary results of a randomized pilot study. Mindfulness, 6(4), 824-835

Mantzios, M., \& Giannou, K. (2018). A real-world application of short mindfulness-based practices: A review and reflection of the literature and a practical proposition for an effortless mindful lifestyle. American Journal of Lifestyle Medicine, 1559-8276.

Mantzios, M., Egan, H., Hussain, M., Keyte, R., \& Bahia, H. (2018). Mindfulness, self-compassion, and mindful eating in relation to fat and sugar consumption: An exploratory investigation. Eating And Weight Disorders - Studies On Anorexia, Bulimia And Obesity, 23(6), 833-840

Marchiori, D., \& Papies, E. (2014). A brief mindfulness intervention reduces unhealthy eating when hungry, but not the portion size effect. Appetite, 75, 40-45

Mollen, S., Rimal, R., Ruiter, R., \& Kok, G. (2013). Healthy and unhealthy social norms and food selection. Findings from a fieldexperiment. Appetite, 65, 83-89

Neff, K. (2003). Self-Compassion: An alternative conceptualization of a healthy attitude toward oneself. Self And Identity, 2(2), 85-101

Neff, K. (2009). The role of self-compassion in development: A healthier way to relate to oneself. Human Development, 52(4), 211-214

Neff, K., \& Germer, C. (2013). A pilot study and randomized controlled trial of the mindful self-compassion program. Journal of Clinical Psychology, 69(1), 28-44

Papies, E., Stroebe, W., \& Aarts, H. (2008). Healthy Cognition: Processes of self-regulatory success in restrained eating. Personality and Social Psychology Bulletin, 34(9), 1290-1300

Papies, E., Barsalou, L., \& Custers, R. (2012). Mindful attention prevents mindless impulses. Social Psychological and Personality Science, 3(3), 291-299

Papies, E., Potjes, I., Keesman, M., Schwinghammer, S., \& van Koningsbruggen, G. (2014). Using health primes to reduce unhealthy snack purchases among overweight consumers in a grocery store. International Journal of Obesity, 38(4), 597-602

Papies, E., Pronk, T., Keesman, M., \& Barsalou, L. (2015). The benefits of simply observing: Mindful attention modulates the link between motivation and behavior. Journal of Personality and Social Psychology, 108(1), 148-170

Robinson, E., Fleming, A., \& Higgs, S. (2014). Prompting healthier eating: Testing the use of health and social norm based messages. Health Psychology, 33(9), 1057-1064

Romero, M., \& Biswas, D. (2016). Healthy-left, unhealthy-right: Can displaying healthy items to the left (versus right) of unhealthy items nudge healthier choices? Journal of Consumer Research, 43(1), 103-112

Schmeichel, B. J., Vohs, K. D., \& Duke, S. C. (2011). Self-control at high and low levels of mental construal. Social Psychological and Personality Science, 2(2), 182-189

Siep, N., Roefs, A., Roebroeck, A., Havermans, R., Bonte, M., \& Jansen, A. (2009). Hunger is the best spice: An fMRI study of the effects of attention, hunger and calorie content on food reward processing in the amygdala and orbitofrontal cortex. Behavioural Brain Research, 198(1), 149-158 
Small, M., Bailey-Davis, L., Morgan, N., \& Maggs, J. (2013). Changes in eating and physical activity behaviors across seven semesters of college. Health Education \& Behavior, 40(4), 435-441

Sprake, E., Lavin, J., Grabowski, P., Russell, J., Featherstone, M., \& Barker, M. (2017). Eating habits associated with body weight gain in female university students. British Food Journal, 119(12), 2571-2582

Steenhuis, I., \& Poelman, M. (2017). Portion size: Latest developments and interventions. Current Obesity Reports, 6(1), 10-17

Stunkard, A., \& Messick, S. (1985). The three-factor eating questionnaire to measure dietary restraint, disinhibition and hunger. Journal of Psychosomatic Research, 29(1), 71-83

Tanay, G., \& Bernstein, A. (2013). State mindfulness scale (SMS): Development and initial validation. Psychological Assessment, 25(4), 1286-1299

Tanton, J., Dodd, L., Woodfield, L., \& Mabhala, M. (2015). Eating behaviours of British university students: A cluster analysis on a neglected issue. Advances in Preventive Medicine, 2015, 1-8

Timmerman, G., \& Brown, A. (2012). The effect of a mindful restaurant eating intervention on weight management in women. Journal of Nutrition Education And Behavior, 44(1), 22-28
Vadeboncoeur, C., Townsend, N., \& Foster, C. (2015). A meta-analysis of weight gain in first year university students: Is freshman 15 a myth? BMC Obesity, 2(1), 22

Versluis, I., \& Papies, E. (2016). Eating less from bigger packs: Preventing the pack size effect with diet primes. Appetite, 100, 70-79

Wansink, B., \& Sobal, J. (2007). Mindless eating. Environment and Behavior, 39(1), 106-123

Wansink, B., Just, D., \& Payne, C. (2009). Mindless eating and healthy heuristics for the irrational. American Economic Review, 99(2), 165-169

Publisher's Note Springer Nature remains neutral with regard to jurisdictional claims in published maps and institutional affiliations. 